\title{
PRODUKTIVITAS ALAT TANGKAP PADA OPERASI PENANGKAPAN UDANG DI KABUPATEN PANGANDARAN SELAMA TAHUN 2015-2019
}

\author{
Productivity of Fishing Gear on Shrimp Catching Operation in Pangandaran Regency \\ Oleh: \\ Izza Mahdiana Apriliani ${ }^{1 *}$, Herman Hamdani ${ }^{1}$, Achmad Rizal ${ }^{1}$ \\ ${ }^{1}$ Fakultas Perikanan dan Ilmu Kelautan, Universitas \\ Padjadjaran, Indonesia \\ *Korespondensi penulis: izza.mahdiana@unpad.ac.id
}

\begin{abstract}
ABSTRAK
Salah satu kabupaten penghasil udang terbesar di Jawa Barat adalah Kabupaten Pangandaran. Besarnya produksi udang di perairan Kabupaten Pangandaran tidak terlepas dari produktivitas alat tangkap yang dioperasikan. Tujuan dari penelitian ini yaitu untuk mengetahui produktivitas alat tangkap penangkap udang di Kabupaten Pangandaran. Riset dilaksanakan bulan Agustus-Oktober 2019. Metode dalam penelitian ini menggunakan metode studi kasus dan data dianalisis secara deskriptif. Hasil penelitian menunjukan bahwa produksi udang mengalami fluktuasi kenaikan, jumlah produksi udang terbesar terjadi pada tahun 2017 yaitu sebesar 965.877,40 kg. Terdapat beberapa alat penangkapan ikan yang dioperasikan untuk menangkap udang di Kabupaten Pangandaran yaitu jaring bernong sebanyak 459 unit, trammel net sebanyak 315 unit, pukat pantai sebanyak 27 unit dan dogol sebanyak 25 unit. Jaring bernong yang dimaksud merupakan alat tangkap bottom gillnet karena menangkap ikan demersal. Nilai produktivitas alat tangkap paling tinggi yaitu alat tangkap dogol sebesar $4,4 \mathrm{~kg} /$ trip dan pukat pantai $4,4 \mathrm{~kg} /$ trip dan nilai produktivitas terendah yaitu pada alat tangkap trammel net sebesar $1,8 \mathrm{~kg} /$ trip dan jaring bernong sebesar $1,4 \mathrm{~kg} /$ trip.
\end{abstract}

Kata kunci: alat tangkap, nelayan, Pangandaran, udang

\begin{abstract}
One of the largest shrimp producing districts in West Java is Pangandaran Regency. The amount of shrimp production in Pangandaran Regency cannot be separated from the productivity of the fishing gear it operates. The purpose of this research is to determine the productivity of shrimp catching gear in Pangandaran Regency. This research carried out in August-October 2019. The method in this study used a case study method and data analyzed descriptively. The results showed that shrimp production had increased fluctuations, largest amount of shrimp production occurred in 2017, amounting to $965,877.40 \mathrm{~kg}$. There are several fishing gears that are operated to catch shrimp in Pangandaran Regency, namely 459 units of bernong net (bottom gillnet), 315 units of trammel net, 27 units of beach seine, and 25 units of dogol (seine net). Bernong as bottom gill net because it catches demersal fish. The highest productivity value of fishing gear is seine net with $4.4 \mathrm{~kg} /$ trip and beach seine $4.4 \mathrm{~kg} /$ trip and the lowest productivity value is trammel net with $1.8 \mathrm{~kg} /$ trip and bottom gill net $1.4 \mathrm{~kg} /$ trip.
\end{abstract}

Key words: fishing gear, fisherman, Pangandaran, shrimp

\section{PENDAHULUAN}

Kabupaten Pangandaran adalah salah satu kabupaten di Jawa Barat yang menghasilkan produksi perikanan tangkap yang cukup besar. Panjang garis pantai Kabupaten Pangandaran yaitu sepanjang 91 $\mathrm{km}$ dengan luas laut sebesar 67.340 ha (Firmansyah et al. 2018). Penyebab besarnya potensi sumberdaya 
perikanan di Kabupaten Pangandaran, karena secara geografis berhadapan langsung dengan Samudera Hindia (Apriliani et al. 2018). Menurut data Dinas Kelautan Perikanan dan Ketahanan Pangan Kabupaten Pangandaran (DKPKP), tahun 2018 jumlah produksi perikanan tangkap mencapai 2.336.949,59 kg dengan nilai nilai produksi Rp72.298.162.105,00. Nilai tersebut menunjukkan betapa pentingnya sektor ini terhadap pendapatan daerah dan masyarakat Pangandaran. Terdapat 10 komoditas penting dengan nilai produksi tertinggi diantaranya adalah udang, layur, tenggiri, tongkol, bawal hitam, bawal putih, kakap merah, kerapu, dan cabuk (DKPKP Kabupaten Pangandaran 2019).

Salah satu komoditas yang menyumbang kontribusi terbesar dalam meningkatkan perekonomian nelayan Pangandaran yaitu udang. Pada tahun 2018 jumlah produksi udang di Kabupaten Pangandaran mencapai 1.081.170,21 kg (DKP Kabupaten Pangandaran 2018). Besarnya produksi udang di Pangandaran menjadikan udang sebagai salah satu pemasukan untuk nelayan di wilayah tersebut. Saat ini produksi udang di Kabupaten Pangandaran berasal dari dua sub sektor yaitu budidaya dan perikanan tangkap. Terdapat beberapa alat tangkap yang dioperasikan nelayan untuk menangkap komoditas udang diantaranya gill net, trammel net, dogol dan pukat pantai. Dogol dan pukat pantai memiliki potensi merusak ekosistem yang dilaluinya, selain itu alat tangkap tersebut memiliki selektivitas rendah. Pada kenyataannya alat tangkap tersebut masih dioperasikan di Pangandaran untuk menangkap udang.

Besarnya produksi udang di perairan Kabupaten Pangandaran tidak terlepas dari produktivitas alat tangkap yang digunakan. Nilai produktivitas alat tangkap didapat dari hasil pembagian antara jumlah bobot hasil tangkapan dengan jumlah upaya penangkapan. Menurut Dewanti (2013) tujuan utama penangkapan yaitu untuk menghasilkan jumlah produksi yang tinggi namun dengan tetap memperhatikan aspek lingkungan agar tercipta perikanan tangkap yang berkelanjutan dan bertanggung jawab.

Kajian alat tangkap untuk komoditas udang ini sangat esensial bagi keberlanjutan sumberdaya udang dimasa mendatang. Perubahan sumberdaya udang dan ekosistem laut dipengaruhi oleh kegiatan penangkapan dan pengaruh antropogenik (Coll et al. 2016). Upaya yang kemudian dikembangkan untuk menentukan alat tangkap komoditas udang diantaranya melihat produktivitas penangkapan. Riset ini dilakukan untuk mendukung upaya tersebut serta dapat dijadikan sebagai dasar riset agar terciptanya perikanan yang berkelanjutan dengan cara melihat kondisi sumberdaya udang dan produktivitas alat tangkap yang digunakan di Kabupaten Pangandaran.

\section{METODE PENELITIAN}

Penelitian ini dilaksanakan pada bulan Agustus-Oktober 2019 di perairan Kabupaten Pangandaran, Jawa Barat (Gambar 1) dengan fokus komoditas udang. Metode riset yang digunakan yaitu metode studi kasus. Studi Kasus merupakan kegiatan ilmiah untuk mendalami suatu kejadian secara terinci dan intensif, baik pada tingkat lembaga, kelompok maupun individu (Rahardjo 2017). Data yang telah dikumpulkan mencakup data primer dan data sekunder.

Data primer dikumpulkan secara observasi langsung di lapangan selama penelitian berupa jenis alat tangkap yang dioperasikan untuk menangkap komoditas udang. Data sekunder yang dikumpulkan pada penelitian ini terdiri jumlah alat tangkap dan jumlah produksi hasil tangkapan. Data tersebut kemudian dianalisis secara deskriptif. Pengertian deskriptif menurut Nazir (2011) adalah studi untuk menemukan fakta dengan pentafsiran yang jelas dan tepat. Tujuannya untuk membuat gambaran atau deskripsi secara sistematis mengenai fakta dan hubungan dari peristiwa yang diselidiki. 


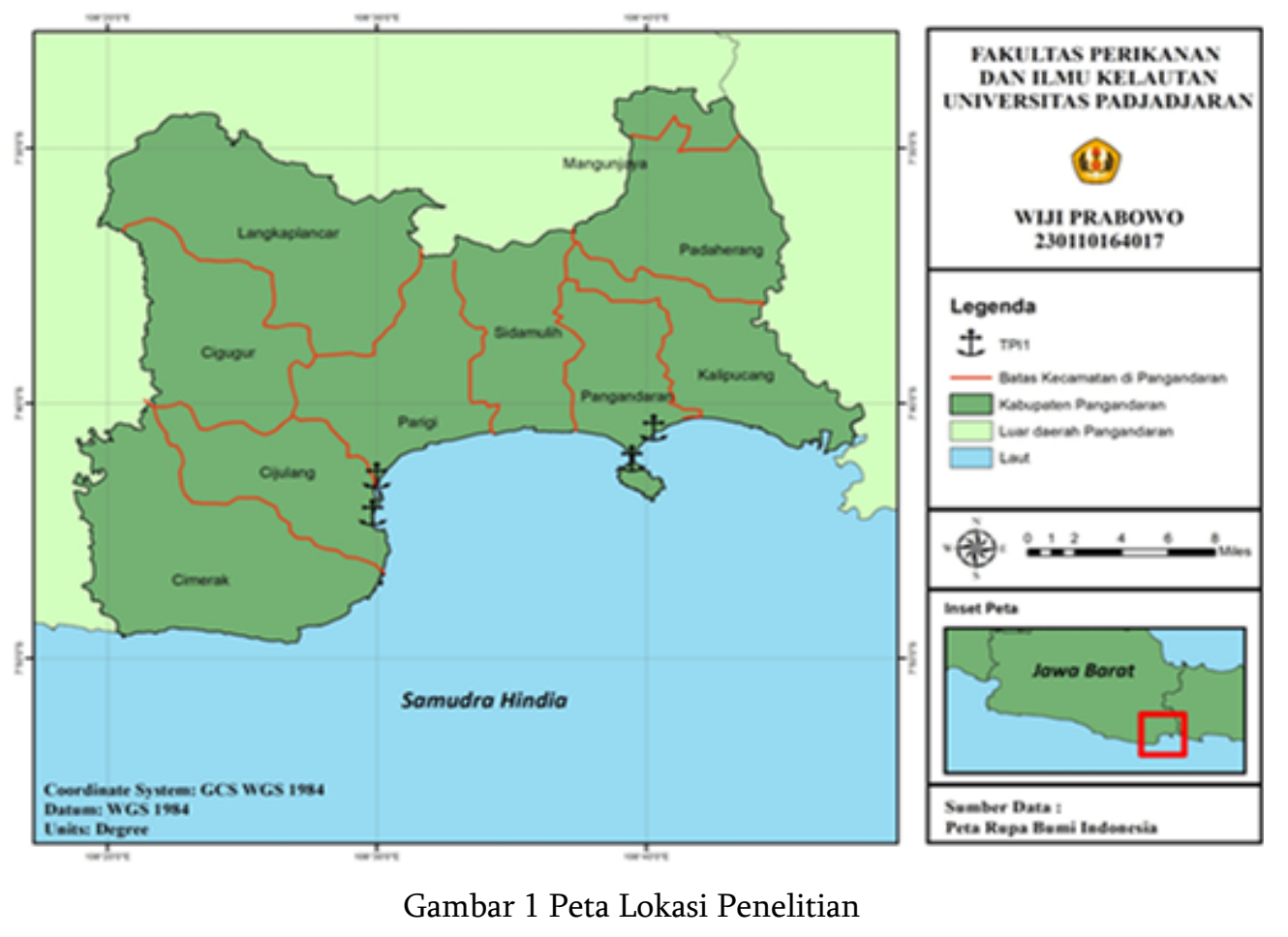

Nilai produktivitas alat tangkap didapat dari nilai CPUE (Catch per Unit Effort) atau jumlah hasil tangkapan per jumlah trip. Menurut Sparre et al. (1999) dalam Dewanti (2013) nilai produktivitas dapat dilihat dari nilai CPUE yang didapatkan. Rumus untuk menentukan nilai produktifitas alat tangkap yaitu sebagai berikut:

$$
C P U E=c / f
$$

Keterangan:

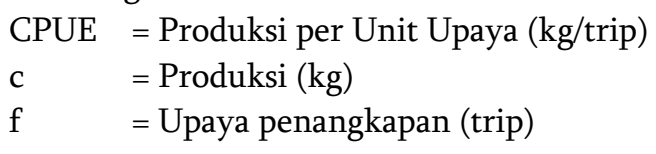

Nilai CPUE ini digunakan untuk mengetahui nilai produktivitas alat tangkap yang paling baik, nilai CPUE yang tinggi menandakan bahwa alat tangkap yang digunakan merupakan alat tangkap yang produktif.

\section{HASIL DAN PEMBAHASAN}

\section{Kondisi Perikanan Kabupaten Pangandaran}

Berdasarkan letak geografis, Kabupaten Pangandaran terletak pada titik koordinat $108^{0} 41^{\prime}-109^{0}$ BT dan 07041'-070-50'LS. Berbatasan langsung dengan kota Banjar dan Ciamis di bagian utara, Samudera Hindia di bagian selatan, Kabupaten Tasikmalaya di bagian barat dan Kabupaten Cilacap di bagian timur. Menurut PERMEN KP NO.01/MEN/2009 tentang Wilayah Pengelolaan Perikanan Republik Indonesia (WPP-RI), Kabupaten Pangandaran berada pada zona WPP-RI 573 yang meliputi Samudera Hindia bagian Selatan Jawa sampai ke selatan Nusa Tenggara, Laut sawu dan Laut Timor bagian barat. Hal tersebut menjadikan Kabupaten Pangandaran memiliki sektor perikanan tangkap dan wisata bahari yang menjadi andalan bagi wilayah tersebut. Menurut Nurhayati (2013), sektor perikanan tangkap dan wisata bahari memberikan kontribusi yang besar terhadap perekonomian masyarakat dan daerah di Kabupaten Pangandaran. Adapun jumlah produksi hasil perikanan tangkap di Kabupaten Pangandaran disajikan pada Tabel 1. 
Tabel 1 Produksi Perikanan Tangkap Kabupaten Pangandaran Tahun 2015-2018

\begin{tabular}{cc}
\hline Tahun & Jumlah Produksi (ton) \\
\hline 2015 & $2.846,068$ \\
2016 & $1.049,492$ \\
2017 & $2.932,152$ \\
2018 & $1.339,462$ \\
\hline
\end{tabular}

Sumber: DKPKP Kabupaten Pangandaran 2019

Tabel 1 menunjukkan bahwa total produksi hasil tangkapan memiliki jumlah yang beragam. Menurunnya retribusi hasil tangkapan ikan di tahun 2016 disebabkan terjadinya paceklik dan cuaca yang tidak mendukung aktivitas nelayan untuk melaut. Curah hujan yang tinggi juga menyebabkan intensitas melaut nelayan berkurang karena terjadi badai. Curah hujan memiliki banyak pengaruh terutama terhadap aktivitas penangkapan nelayan (Rais dan Herlan 2015). Salah satu faktor yang mempengaruhi pendapatan nelayan yaitu jumlah hasil tangkapannya. Pendapatan nelayan akan meningkat jika jumlah hasil tangkapan yang dihasilkan meningkat.

\section{Produksi Udang di Kabupaten Pangandaran}

Pangandaran memiliki produksi sumberdaya ikan yang melimpah khususnya udang. Komoditas udang meliputi udang jerbung (Penaeus merguiensis), udang dogol (Metapenaeus monoceros), udang krosok (Parapenae sculptilis), udang rebon (Mysis relicta) dan udang jambu (Metapenaeus lysianassa). Jumlah produksi komoditas udang disajikan pada Tabel 2.

Tabel 2 Produksi Komoditas Udang di Kabupaten Pangandaran

\begin{tabular}{|c|c|c|c|c|c|}
\hline \multirow{2}{*}{ Spesies } & \multicolumn{4}{|c|}{ Produksi (kg) } & \multirow{2}{*}{$\begin{array}{l}\text { Rata-Rata } \\
\quad(\mathrm{kg})\end{array}$} \\
\hline & 2015 & 2016 & 2017 & 2018 & \\
\hline $\begin{array}{l}\text { Udang Krosok } \\
\text { (Parapenaeopsis sculptilis) }\end{array}$ & $178.843,70$ & $81.246,20$ & $41.028,50$ & 120.164 & $105.320,60$ \\
\hline $\begin{array}{l}\text { Udang Jerbung (Penaeus } \\
\text { merguiensis) }\end{array}$ & $49.097,70$ & $43.017,80$ & $47.989,50$ & $54.709,95$ & $48.703,74$ \\
\hline $\begin{array}{l}\text { Udang Rebon (Mysis } \\
\text { relicta) }\end{array}$ & 493.592 & $78.415,60$ & $743.851,50$ & $245.198,80$ & $390.264,48$ \\
\hline $\begin{array}{l}\text { Udang Jambu } \\
\text { (Metapenaeus lysianassa) }\end{array}$ & 22,35 & 26,80 & 687,20 & 3,90 & 185,06 \\
\hline $\begin{array}{l}\text { Udang Dogol } \\
\text { (Metapenaeus monoceros) }\end{array}$ & $144.579,50$ & $209.232,50$ & $132.320,70$ & $117.481,40$ & $150.903,52$ \\
\hline Total & $866.135,3$ & $411.938,9$ & $965.877,40$ & $537.558,10$ & $695.377,40$ \\
\hline
\end{tabular}

Sumber: DKP Kabupaten Pangandaran 2015-2018

Tabel 2 menunjukan total produksi komoditas udang yang dihasilkan memiliki jumlah yang beragam selama tahun 2015 sampai 2018 dan cenderung mengalami kenaikan setiap tahunnya. Jumlah produksi udang pada tahun 2016 dan 2018 mengalami penurunan produksi hingga dua kali lipat dari jumlah produksi tahun 2015 dan tahun 2017. Menurut Rifaldi (2019), penurunan produksi perikanan tahun 2016 disebabkan karena curah hujan sangat tinggi, sehingga pakan alami untuk ikan di laut sangat sedikit yang menyebabkan ikan tidak bisa berproduksi dengan banyak. Besarnya curah hujan di Pangandaran menyebabkan nelayan tidak pergi melaut.

Udang rebon merupakan salah satu komoditas yang memiliki jumlah produksi lebih banyak yaitu sebesar 1.561.057,90 kg. Hal tersebut menunjukkan bahwa jumlah udang rebon di perairan Kabupaten Pangandaran sangat melimpah. Menurut Dwipayana et al. (2018), hasil tangkapan di pantai timur Pangandaran didominansi oleh udang rebon. Jumlah produksi udang terendah yaitu terdapat pada komoditas udang jambu sebesar 740,25 kg. Udang rebon dan udang jambu memiliki morfologi 
yang hampir sama, hal yang membedakannya yaitu terdapat pada ukuran udang jambu yang sedikit lebih besar dan tubuhnya memiliki warna merah muda seperti halnya warna pada buah jambu merah.

\section{Alat Tangkap Udang}

Alat tangkap yang dioperasikan untuk penangkapan udang di Kabupaten Pangandaran disajikan pada Tabel 3.

Tabel 3 Alat Tangkap yang Beroperasi di Kabupaten Pangandaran

\begin{tabular}{ccc}
\hline No & Jenis Alat Tangkap Ikan & Jumlah (unit) \\
\hline 1 & Trammel net & 315 \\
2 & Dogol & 25 \\
3 & Pukat pantai & 27 \\
4 & Jaring bernong & 459 \\
\hline
\end{tabular}

Sumber: Bidang Perikanan Tangkap DKPKP Kabupaten Pangandaran 2019

Menurut data yang disajikan pada Tabel 3 jenis alat tangkap yang banyak digunakan untuk melakukan penangkapan udang yaitu jaring bernong dengan jumlah 459 unit dan alat tangkap yang sedikit digunakan yaitu dogol. Jaring bernong yang dimaksud adalah alat tangkap bottom gill net karena menangkap ikan demersal. Jaring bernong memiliki mesh size 1 inchi dan memiliki panjang 350 meter per 10 pieces. Jaring bernong banyak dioperasikan oleh nelayan karena memiliki beberapa keuntungan, diantaranya adalah mudah dioperasikan dan biayanya relatif murah. Menurut Pramesthy et al. (2020) gill net memiliki teknik pengoperasian yang bersifat sederhana sehingga dapat menjaga keselamatan nelayan.

Jenis alat tangkap ramah lingkungan yang baik digunakan untuk menangkap udang yaitu trammel net (WWF Indonesia 2015). Hasil penelitian Iskandar (2010) 50\% hasil tangkapan dari alat tangkap trammel net yaitu udang. Trammel net merupakan alat yang efektif digunakan oleh nelayan skala kecil karena tidak membutuhkan modal yang besar. Trammel net terdiri atas tiga lapis jaring dimana ketiga jaring tersebut berbahan dasar dari nylon monofilament. Jaring lapisan dalam (inner net) memiliki ukuran mesh size sebesar 1,75 inchi dan lapisan luar (outer net) memiliki mesh size sebesar 5,2 inchi serta memiliki panjang antara 105-140 meter. Prinsip pengoperasian trammel net adalah dengan cara dihanyutkan mengikuti arah arus atau diseret sehingga dapat menyapu dasar laut yang dilaluinya, jenis dari hasil tangkapan alat tangkap ini yaitu ikan demersal salah satunya udang (Rihmi et al. 2017).

Sedikitnya jumlah alat tangkap dogol dan pukat pantai karena kedua alat tangkap tersebut merupakan contoh alat tangkap yang dilarang dalam pengoperasiannya, khususnya di Indonesia. Berdasarkan PERMEN-KP No.2 Tahun 2015 tentang 'Larangan Penggunaan Alat Penangkapan Ikan Pukat Hela dan Pukat Tarik, Dogol dan Pukat Pantai' adalah jenis alat alat tangkap yang pengoperasiannya dilarang karena kedua alat tangkap tersebut masuk ke dalam pukat tarik berkapal. Menurut Fahmi dan Yonvitner (2016), dogol dapat merusak ekosistem yang dilaluinya dan memiliki selektivitas yang rendah. Alat tangkap dogol dan pukat pantai memiliki prinsip pengoperasian dengan cara melingkari gerombolan ikan lalu dilakukan penarikan agar gerombolan ikan dapat tertangkap pada jaring.

\section{Produktivitas Alat Tangkap}

Produktivitas alat tangkap merupakan nilai yang diperoleh dari jumlah hasil tangkapan terhadap upaya penangkapan atau penggunaan sumberdaya (Herjanto 2006). Upaya penangkapan (effort) sebagai input dan hasil tangkapan per satuan waktu sebagai output yang dihasilkan (Zulbainarni 2012). Berikut ini adalah nilai produktivitas tiap alat tangkap yang ada di Kabupaten Pangandaran disajikan pada Tabel 4. 
Tabel 4 Jumlah Produksi dan Jumlah Trip Alat Tangkap dari Tahun 2015-2019

\begin{tabular}{lccc}
\hline \multicolumn{1}{c}{ Alat Tangkap } & Produksi (Ton) & Effort (Trip) & Produktivitas (Ton/Trip) \\
\hline Trammel Net & 111,2 & 62540 & 0,0018 \\
Dogol & 17,2 & 3974 & 0,0044 \\
Pukat Pantai & 12,2 & 2347 & 0,0044 \\
Jaring Bernong & 12,74 & 90753 & 0,0014 \\
\hline
\end{tabular}

Berdasarkan Tabel 4 dapat dilihat bahwa jumlah produksi dari masing-masing alat tangkap menunjukan nilai yang sangat beragam. Jaring bernong dan trammel net memiliki produktivitas yang rendah, namun alat ini banyak dimiliki oleh nelayan. Kondisi sumberdaya perikanan dipengaruhi oleh banyaknya kepemilikan alat tangkap oleh nelayan, banyak nelayan yang memiliki alat tangkap trammel net namun alat tangkap tersebut memiliki produktivitas yang lebih rendah dari trawl (Jamal 2015). Alat tangkap yang digunakan secara efisien dan efektif akan berpengaruh terhadap meningkatnya produksi hasil tangkapan (Hamdan 2007).

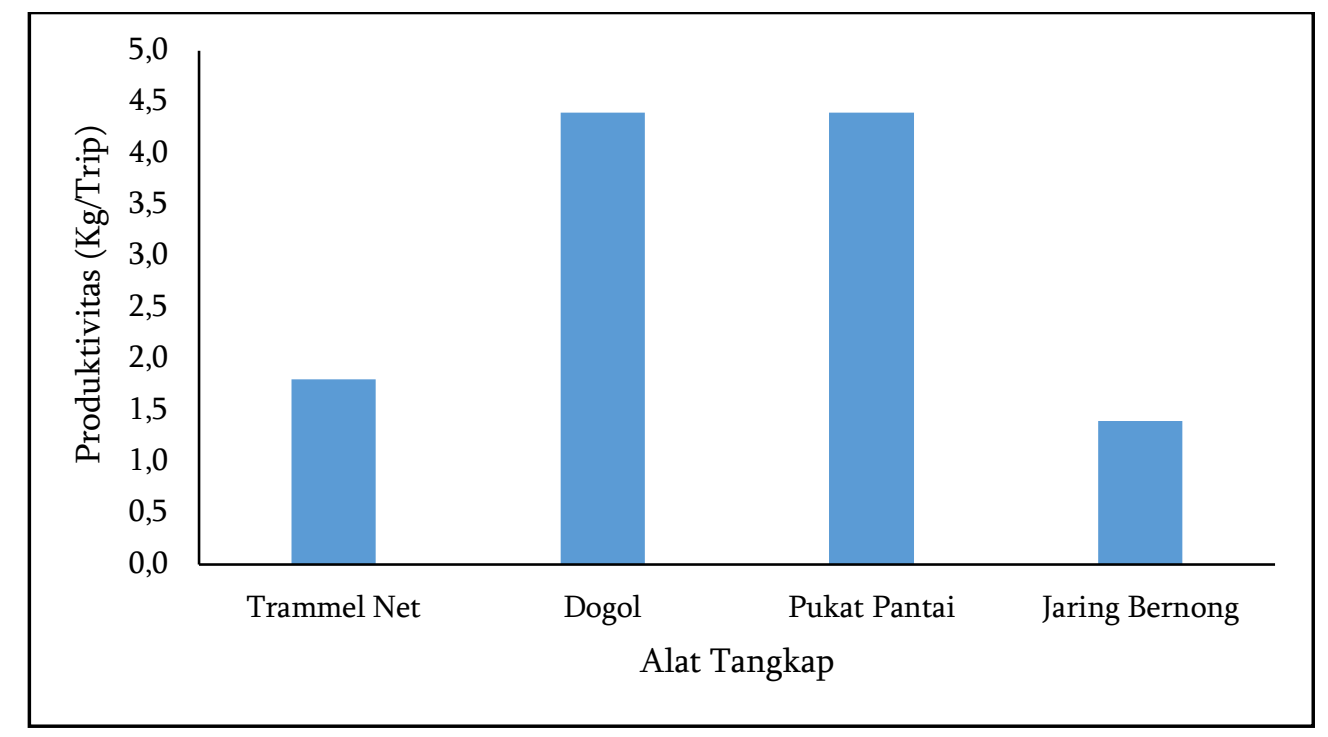

Gambar 2 Produktivitas Alat Tangkap

Berdasarkan Gambar 2, menunjukan nilai produktivitas alat tangkap paling tinggi di Kabupaten Pangandaran yaitu alat tangkap dogol sebesar $4,4 \mathrm{~kg} /$ trip dan pukat pantai $4,4 \mathrm{~kg} /$ trip. Hal tersebut karena dogol dan pukat hela memiliki upaya penangkapan (effort) yang tinggi namun hasil tangkapannya rendah. Pukat pantai dan dogol memiliki nilai produktivitas yang tinggi tetapi tidak cocok dikembangkan karena bersifat tidak ramah lingkungan, dan dapat merusak ekosistem laut.

Produktivitas alat tangkap terendah yaitu pada alat tangkap trammel net sebesar 1,8 kg/trip dan jaring bernong sebesar $1,4 \mathrm{~kg} /$ trip. Salah satu hal faktor yang menyebabkan rendahnya produktivitas kedua alat tangkap tersebut karena tingginya upaya penangkapan yang dilakukan di Kabupaten Pangandaran. Semakin tinggi upaya penangkapan maka akan semakin kecil produktivitas alat tangkapnya (Zulfikar 2012).

Alat tangkap yang memiliki tingkat keramahan yang kurang baik cenderung memiliki nilai produktivitas yang tinggi, sedangkan alat tangkap yang memiliki tingkat keramahan yang baik memiliki nilai produktivitas yang rendah atau kurang produktif. Pengembangan teknologi penangkapan ikan yang berkelanjutan harus seimbang antara produktivitas dan tingkat keramahan lingkungan karena keduanya merupakan salah satu indikator terciptanya kelestarian sumberdaya perikanan bertanggung jawab dan berkelanjutan. 


\section{KESIMPULAN DAN SARAN}

Produksi udang di Kabupaten Pangandaran tahun memiliki jumlah yang beragam, jumlah produksi udang tertinggi yaitu pada tahun 2017 sebesar 965.877,40 kg. Alat tangkap yang banyak dioperasikan oleh nelayan untuk penangkapan udang yaitu jaring bernong, trammel net, dogol dan pukat pantai. Nilai produktivitas alat tangkap selama tahun 2015-2019 yang paling tinggi yaitu pada alat tangkap dogol sebesar 4,4 kg/trip dan pukat pantai sebesar 4,4 kg/trip. Pukat pantai dan dogol memiliki nilai produktivitas yang tinggi tetapi tidak cocok dikembangkan karena bersifat tidak ramah lingkungan dan dapat merusak ekosistem laut.

\section{DAFTAR PUSTAKA}

Apriliani IM, Nurrahman YA, Dewanti LP, Herawati H. 2018. Determination of Potential Fishing Ground for Hairtail (Trichiurussp) Fishing Based On Chloropyll-A Distribution and Sea Surface Temperature in Pangandaran Regency Waters, West Java, Indonesia. AACL Bioflux. 11(4):10471054.

Coll MJ, Shannon K, Kleisner MJ, Juan-Jorda A, Bundy AG, Akoglu D, Banaru JL, Boldt MF, Borges AM, Cook I, Diallo C, Fu CJ, Fox D, Gascuel LJ, Gumey T, Hattab JJ, Heymans D, Jouffre B, Knight S, Kucukavsar SI, Large CP, Lynam A, Machias KN, Marshall H, Masski H, Ojaveer C, Piroddi J, Tam D, Thiaw MA, Torres M, Travers-Trolet K, Tsagarakis I, Tyck GIVD, Meeren D, Yemane SG, Zador S, Yunne-Jai. 2016. Ecological Indicators to Capture The Effects of Fishing on Biodiversity and Conservation Status of Marine Ecosystems. Ecological Indicators. 60: 947962.

[DKPKP] Dinas Kelautan, Perikanan dan Ketahanan Pangan Kabupaten Pangandaran. 2019. Statistik Perikanan Kabupaten Pangandaran. Laporan Tahunan. Pangandaran (ID): DKPKP Kabupaten Pangandaran.

[DKP] Dinas Kelautan dan Perikanan Kabupaten Pangandara. 2018. Data Produksi TP Kabupaten Pangandaran Kabupaten Pangandara. 2018. Laporan Tahunan. Pangandaran (ID): Dinas Kelautan dan Perikanan Kabupaten Pangandaran.

Dewanti LP. 2013. Tingkat Keramahan dan Produktivitas Alat Tangkap di Kabupaten Indramayu (Studi Kasus; PPI Karangsong) [skripsi]. Jatinangor (ID): Fakultas Perikanan dan Ilmu Kelautan Universitas Padjadjaran.

Dwipayana MF, Sunarto, Rostini I, Apriliani IM. 2018. Hasil Tangkapan Bagan Apung dengan Waktu Hauling Berbeda di Pantai Timur Pangandaran. Jurnal Perikanan dan Kelautan. 9(1):112-118.

Fahmi, Yonvitner. 2016. Keanekaragaman Hayati dan Kepadatan Stok Ikan Demersal di Perairan Tambelan, Laut Natuna. Jurnal Ilmu dan Teknologi Kelautan Tropis. 8(2):503-516.

Firmansyah T, Hasan Z, Afrianto E, Apriliani IM. 2018. Pemetaan Daerah Penangkapan Potensial Ikan Layur (Trichiurus sp) di Perairan Pangandaran Jawa Barat. Jurnal Airaha. 7(1):006-012.

Hamdan. 2007. Analisis Kebijakan Pengelolaan Perikanan Tangkap Berkelanjutan di Kabupaten Indramayu [disertasi]. Bogor (ID): Institut Pertanian Bogor.

Herjanto E. 2006. Manajemen Operasi. Jakarta [ID] : PT. Grasindo.

Iskandar D. 2010. Perbandingan Hasil Tangkapan Udang dengan Menggunakan Lapdu, Giltong dan Trammel Net di Perairan Saengga Kabupaten Teluk Bintuni. Jurnal Saintek Perikanan. 6(1):2229.

Jamal M. 2015. Selektivitas Alat Tangkap Trammel Net Terhadap Udang Penaid di Kabupaten Takalar Provinsi Sulawesi Selatan. Jurnal Ilmu Kelautan dan Perikanan. 25(2):96-105. 
Nazir M. 2011. Metode Penelitian. Jakarta (ID): Ghalia Indonesia.

Nurhayati A. 2013. Analisis Potensi Lestari Perikanan Tangkap di Kawasan Pangandaran. Jurnal Akuatika. 4(2):195-209.

Peraturan Menteri Kelautan dan Perikanan Nomor 1 Tahun 2009. Wilayah Pengelolaan Perikanan Republik Indonesia. Jakarta.

Peraturan Menteri Kelautan dan Perikanan Nomor 2 Tahun 2015. Larangan Penggunaan Alat Penangkap Ikan Pukat Hela (Trawls) dan Pukat Tarik (Seine Nets) di Wilayah Pengelolaan Perikanan Negara Republik Indonesia. Jakarta.

Pramesthy TD, Mardiah RS, Shalichaty AF, Arkham MN, Bayu R., Haris K, Kelana PP, Djunaidi. 2020. Analisis Alat Tangkap Jaring Insang (Gill Net) Berdasarkan Kode Etik Tatalaksana Perikanan Bertanggung Jawab di Perairan Kota Dumai. Aurelia Journal. 1(2):103-112.

Rais AH, Herlan R. 2015. Pengaruh Curah Hujan Terhadap Kondisi Perairan dan Hasil Tangkapan Ikan di Estuari Sungai Barito. Jurnal Penelitian Indonesia. 21(2):131-138.

Rahardjo M. 2017. Studi Kasus dalam Penelitian Kualitatif. Malang (ID): Universitas Islam Negeri.

Rifaldi F. 2019. Analisis Faktor-Faktor yang Mempengaruhi Pendapatan Nelayan di Kecamatan Pangandaran Kabupaten Pangandaran [skripsi]. Tasikmalaya (ID): Universitas Siliwangi.

Rihmi MK, Puspito G, Wahyu RI. 2017. Modifikasi Konstuksi Trammel Net: Upaya untuk Meningkatkan Hasil Tangkapan. Jurnal Teknologi dan Kelautani. 8(2):169-178.

[WWF]. World Wide Fund for Nanure Indonesia. 2015. Penangkapan Udang Ramah Lingkungan dengan Alat Tangkap Jaring Tiga Lapis. Jakarta (ID): Graha Simatupang.

Zulfikar. 2012. Pengelolaan Perikanan Tangkap Berkelanjutan di Perairan Selatan Pelabuhanratu [tesis]. Depok (ID): Pascasarjana Universitas Indonesia.

Zulbainarni N. 2012. Teori dan Praktik Pemodelan Bioekonomi dalam Pengelolaan Perikanan Tangkap. Bogor (ID): IPB Press. 